\title{
HIV AND AIDS, WORLDVIEWS AND TRANSFORMATION IN HIGHER EDUCATION
}

\section{A. Verhoef}

School of Philosophy

North-West University

Potchefstroom, South Africa

e-mail: Anne.verhoef@nwu.ac.za

\section{ABSTRACT}

Higher education students need to understand HIV not only as a disease, but as a social issue that intersects with other critical social and human rights issues in the South African context. To change students' attitude to HIV and AIDS, they need to identity, analyse and critique their worldviews. In this article I explain how this is done through a compulsory 'Understanding the social and cultural world' module within the Faculty of Arts. The aim of this module is to broaden students' worldviews, to help them to be open to diversity, and to be able to gain a deeper and more nuanced view, not only of HIV and AIDS, but also of the intersecting social issues. Using a critical pedagogical approach, I explain how I engage students to interrogate their own worldviews, and offer some evidence of shifts in their thinking towards a more inclusive ontology, necessary to enable them to take their place as leaders in our diverse and complex society.

Keywords: AIDS, curriculum, HIV, human rights, intersectionality, transformation, worldviews

\section{INTRODUCTION}

One of the reasons why HIV is largely excluded from the curriculum in higher education may be that it is easier for curriculum makers to use the excuse of student 'AIDS fatigue' than to engage in critical self-reflection on issues of social justice and transformation and how they intersect with their personal beliefs and their scholarly field (HEAIDS 2007, 5). The opportunity might therefore be missed in higher education to engage students not only around HIV and AIDS, but also how their worldviews intersect with the broader implications of the pandemic. I argue that the integration of HIV education, within the curriculum linked to worldview, not only assists students to develop the skill of critical self-reflection, but also enables them to adopt a broader, more inclusive worldview. When students better understand the intersectionality of HIV and AIDS with other social constructs (like race, gender, poverty, violence, human rights, culture) they are better able to use their learning to make a positive contribution to our diverse, complex society. This aspect of the curriculum is of huge importance because it helps students to learn not only on an informational level about social 
issues like HIV and AIDS, but also how to 'be' in this complex world (Steyn 2014) so that they may address these issues from a more inclusive stance.

How HIV and AIDS are linked to worldviews is first discussed in this article. The importance of this link will be indicated by using the idea of Brown and Beck (2009) (they analysed the effectiveness of certain HIV prevention posters to communicate to people with different worldviews) in order to create a pedagogical space to enhance the critical diversity literacy (Steyn 2014) of students. The second part of the article will critically examine how the link between HIV prevention posters and worldviews can be used as a vehicle to broaden students' thinking about their own worldviews and to encourage the adoption of a more inclusive worldview. This will be done through a critical reflection on an 'Understanding the social and cultural world' module (Verhoef 2014) developed and taught by the author. The last part of the article will discuss and evaluate the implication of students adopting a more inclusive worldview, leading to greater awareness of diversity and the intersectionality of HIV and AIDS with other social issues. I will argue that transformation of student thinking is enhanced by increasing their understanding of and attitude towards HIV and AIDS in society.

The method followed in this article is one of critical reflection on not only the relevant literature in this field of study, but also on my experience as lecturer and developer of this compulsory 'Understanding the social and cultural world' (UTW) module which addresses HIV and AIDS and their relation to worldviews and other social issues. The content of this module is controlled to a large extent by a Senate Committee which advocates the inclusion of three philosophical paradigms - the Western, Christian and African worldviews. While this prescription of content is debatable, this article explains how I attempt to shift student thinking within these prescribed boundaries. This is not an empirical study, but rather a critical analysis of my engagement with students and their oral and written responses in class and assignments. This critical reflection gave me insight into the challenges of integrating HIV into the curriculum. This link between HIV and AIDS and worldviews can help to create a curriculum that challenges and disrupts student thinking, moving them from an exclusive and narrowminded worldview which is judgmental or apathetic towards HIV, to one that is more open to diversity and is based on a deeper understanding of the intersectionality of various social issues in the South African context.

\section{AN OVERVIEW OF THE COMPULSORY UNDERSTANDING THE WORLD MODULE}

The UTW module is a second year second semester module which is compulsory for all 
students. Working within the parameters set by the Senate Committee, I developed it specifically for the Arts Faculty's students who aspire to a career in the social sciences. I have been teaching and developing it for the last six years. On average, every year about 300 students register for the module. Although there is some diversity in the classes, about 70 per cent of the students are White, mostly Afrikaans speaking with the rest coming from the Black, Coloured and Indian population.

The UTW module is structured in three parts, namely 1) the discussion of HIV and AIDS and the link with worldviews through the medium of HIV prevention posters, 2) critical discussion of various worldviews, and 3) discussion of other social issues like racism, corruption and poverty and their link to worldviews. In the first part of the module, I use the article of Brown and Beck (2009) on the effectiveness of certain HIV prevention posters for communicating a message to people with specific worldviews. These authors found that posters which are tailor-made for specific worldviews, are able to better convey the HIV prevention message to that particular group. I use these posters to help students understand their own worldviews (they identify which posters resonate with them the most) and to see the link of their worldviews to HIV and AIDS. In the second part I create a pedagogical space to enhance the critical diversity literacy of students. The development of critical diversity literacy allows students to become aware of their own possible bias and 'prevalent structures of oppression' in the different ecologies within which they operate (Steyn, McEwan and Kelly 2010, 2). This is done through an analysis and critique of their own worldviews. The last part of the module explains the intersectionality of HIV and AIDS with other social issues. The structure of the UTW module links directly to set outcomes. On completion of the module, students should:

1. have a fundamental knowledge base of a selection of worldviews and ideologies and demonstrate their critical understanding through an ability to compare their nature and function, as well as different contemporary manifestations of these worldviews and ideologies;

2. have the ability to understand the interrelatedness of phenomena such as occur in natural and social systems, and from this vantage point, analyse and evaluate real life problems or case studies based on core issues of our time, such as poverty, constant change, human rights, HIV and AIDS, power abuse, corruption, racism, xenophobia, etc.; and

3. be able to articulate their personal worldview and use it as a point of departure for arguing and communicating feasible solutions to core issues and problems of our time in a typical academic manner. 
In line with these UTW module outcomes, my aim in this module is to equip students to find ways to develop new understandings of the social issues in our country, how they are interrelated with each other and how positive social change can only ensue when these sociostructural links are made and addressed. The compulsory UTW module is not a specialised course on HIV and AIDS, but it is the only space in the programme where it is addressed. The UTW module aims to link social issues to the students' worldviews and to encourage change in these worldviews so that students can better understand the complex aetiology and consequences of social issues like HIV/AIDS. This link is complex to make, because students firstly have to develop an understanding of the concept of worldview (as a framework which orientates people 'to the world around them and to the ultimate issues of life' (Naugle 2002, 10), before they can identify their own. Furthermore, they are not used to having their worldview challenged, as is done in this module. I ask them to reflect on how they think about life, reality, themselves - and then to rethink how they conceptualise social issues like HIV and AIDS.

\section{WORLDVIEWS AND HIV AND AIDS}

The link between worldview and the complexities of HIV and AIDS might be obvious for academics working in this field, but for most students it is something they need to discover. Their worldviews are mostly 'hidden', as explained by Wilkens and Sanford $(2009,13)$. These authors contend that there are forces, often unseen, that shape every decision we make and every action we take. This is what they call hidden worldviews. They argue that 'these hidden, life-shaping values and ideas are not promoted through organized religions or rival philosophies but fostered by cultural habits, lifestyles and the institutional structures of society' $(2009,14)$. Worldviews are 'all around us, but are so deeply embedded in culture that we don't see them. In other words, these worldviews are hidden in plain sight' $(2009,12)$. To really discover your worldview, critical reflection on your own value system should take place. It is in this regard that the HIV prevention posters - as discussed in the article of Brown and Beck (2009) function in the UTW module as an excellent tool. This will be explained later in more detail. First let me address the question: What is a worldview and how does it differ, for example, from a 'cultural perspective'?

The concept worldview is used very broadly in the UTW module and of course a lot more can be said on a technical and philosophical level about worldviews. Worldviews may for example change during peoples' lives and worldviews may even overlap. The term cannot be used to rigidly categorize people and the intention of using it in this UTW module is not to be 
reductive of the complexities and uniqueness of individuals, but rather to give an indication of some dominant or prominent system of values that function in peoples' life. In the Western intellectual tradition ${ }^{1}$ a worldview has generally been treated as 'a comprehensive and unified system of thought' (Olthuis 1989, 1). All the factors of life (biophysical, emotional, rational, religious), according to Olthuis, affect worldview formation simultaneously and interdependently. He describes a worldview as a vision of life - 'a framework or set of fundamental beliefs through which we view the world and our calling and future in it' (Olthuis 1989, 2). He makes the important point - in terms of this article's focus - that a worldview serves as the interpretative and integrative framework for all life. Worldview is thus a broader concept than 'culture' which is more difficult to change as it involves fundamental beliefs. It may however not be necessary to change one's whole worldview to be more open to the complexities of HIV, but just to make certain changes within it - or at least to become aware of the restrictions of one's worldview in understanding HIV and AIDS. Olthuis says for example that although one's worldview receives its culminating validation in faith, a 'worldview is open to justification, challenge, modification, and change' (Olthuis 1989, 8).

The above definition of worldviews is significant in the sense that it allows for change. The problem with the definition - in the classroom situation - is that it is too theoretical. The students need to discover and identify their worldviews on a much more personal level to understand how they affect their attitude towards social issues like HIV and AIDS. Without knowledge of their own worldviews, and without the recognition of HIV and AIDS as a social issue, they cannot make the link between the two. It is in this regard where the HIV prevention posters play an important role in this UTW module. Students, in my experience, have a very limited, bio-medical understanding of HIV and AIDS. They know the medical facts of the virus, they know about prevention and that they should not stigmatise those who are infected and affected (Wood 2011a). They do not, however, understand HIV and AIDS as an 'intellectual conundrum' with all the social challenges it presents (Volks 2012, 1). Because they have a reductive understanding of $\mathrm{HIV}$ as a disease, they struggle to see the intersectionality of HIV/AIDS with social, economic, political and human rights (Wood 2011b) - all issues that are strongly linked and influenced by one's worldview. The potential link of HIV and AIDS to students' worldviews is thus lost if they understand it only in medical terms.

For example, my predominantly middle class, conservative, religious (White) students tend to refer to it as a disease of poor, Black people or as an act of God to punish immoral behaviour, an acceptable consequence of transgressing scripture. These conceptualizations which the students commonly hold in the beginning of the course are already an indication of 
the strong link of HIV and AIDS with worldviews. Their conceptualization of the disease in terms of a specific culture and income group normally excludes their own 'safe' group, enabling them to 'other' it and to deny any responsibility for its causes and consequences. The universal problem of HIV and AIDS - the fact that it affects everyone, not only specific demographic groups - is thereby denied. This is typical of the individualistic and self-centred worldview of modern Western people (Van der Walt 2003, 112; Taylor 2007, 474). ${ }^{2}$ The truth is however that HIV and AIDS intersect with many pressing social issues - both as a cause and consequence (Volks 2012, 8) - and so none of us can deny that we are in some way responsible for prevention and dealing with the complex consequences it has for society in general.

The students' initial conceptualization of HIV and AIDS in terms of God's punishment for immoral sexual behaviour (with the accompanying stigmatization) also immediately exposes the link between HIV and AIDS and their worldviews. Sexual behaviour is always understood (and judged) from within a worldview perspective. Alan Goldman (2007) says for example that 'sexual activity ... has become imbedded in layers of cultural, moral, and superstitious superstructure (2007, 282). To speak of HIV and AIDS as 'God's judgment and punishment for immoral sexual behaviour' is a good example of the embeddedness of sexuality within a specific religious worldview. In this case the judgemental nature of the religious worldview prohibits new understandings of HIV and AIDS and inhibits favourable discourse around the topic. The question then becomes (from a curriculum perspective): How can this worldview be disrupted, changed and transformed, to help students become open for new possibilities, for new knowledge and for a more inclusive approach towards HIV and AIDS?

My argument is that this transformation can only be done once students have identified their own worldview and thought about the implications of it for thinking about how they conceptualise and respond to social issues like HIV and AIDS. If students have a good understanding of the concept worldview, the link becomes clearer. In other words, to think about HIV and AIDS without interrogating (or at least acknowledging) one's own worldview is impossible. This link and the important implications of it should therefore be critically considered in any social science curriculum on HIV education in order to engage students on a deeper level with the complexities and the intersectionality of it, and also to reciprocally allow the challenges to their worldview presented by HIV and AIDS to disrupt their worldview in order to make it more inclusive and open to diversity. This is the aim of the compulsory UTW module. Students should in other words become aware of how their dominant worldview determines how they conceptualize HIV and AIDS, how it may contribute to 'othering', to an attitude of 'it will never happen to me' and 'I am superior to such people'. Such beliefs and the 
underlying worldviews that spawn them need to be challenged if students are to develop the qualities and embody the values we state our teaching aims to inculcate in graduates - equality, respect, human dignity and justice http://www.nwu.ac.za/sites/www.nwu.ac.za/files/files/i-institutional-information/annualreport/static-content/NWU\%20Annual_report_2006.pdf.)

In the next section I will explain how the HIV prevention posters (Brown and Beck 2009) are used to encourage students to engage with the questions of 'What is my worldview?' and then: 'Should my worldview change, and how?' These questions are an important first step in thinking about the complexities of HIV and AIDS and an important tool in this process of challenging one's worldview.

\section{USE OF HIV PREVENTION POSTERS AS A PEDAGOGICAL STRATEGY FOR DISRUPTING STUDENT THINKING}

The 2009 article of Brown and Beck, 'How to tailor public communications about HIV/AIDS to different worldviews', asks the question why some communication campaigns about preventing HIV deeply impact a wide population, while others fail. Their answer to this question is that certain messages resonate better with people who hold certain worldviews. They discuss the fundamentals of tailoring HIV communication to a variety of worldviews within any audience. In their discussion five worldviews are identified (and named as colours) and explained in detail. They take care to state that these worldviews are not rigid categorizations of people and that the worldviews identified by them do not fully represent the complexity and depth of individuals and their cultural contexts. I explain only three of the worldviews (purple, red, blue) and only the values of each worldview (Brown and Beck 2009, 6) in order not to repeat their article but just to make their argument clearer to students. The three listed are developed further in the UTW module through other literature as the 'African worldview', the 'modern Western worldview' and the 'Christian worldview'. These three are chosen because they are the ones assumed by the Senate Committee to be those that our students would ascribe to. Whether this is the case or not, requires further study.

1. The purple worldview has the following values: magic or unforeseen forces; ancestral ways; customs; rituals and rites of passage; omens; council of elders; lineage; shamans and witches (Brown and Beck 2009, 6). This worldview is developed further and explained as an African worldview through the work of Van der Walt (2003).

2. The red worldview has values of 'assertion of self over the system, power and action, 
freedom, calling the shots, enjoying oneself without regret, dominating, being daring' (Brown and Beck 2009, 6, 10). This worldview has strong affinity with the modern Western worldview with its emphasis on individualism and autonomy.

3. The blue worldview appreciates stability, a purposeful life, truth (secular or religious), laws, regulations, sacrificing for a transcendent Cause (Brown and Beck 2009, 6, 14). These values are to a large extent aligned to the religious worldview of Christianity, but need not be understood exclusively as religious (or only as the Christian religion).

Students struggled to understand these worldviews when I discussed them theoretically. They did not even try to make a connection to their own lives and worldviews. I thus decided to try a more interactive approach. The alternative approach started not with a theoretical explanation of worldviews, but with the posters from Brown and Beck's article on the prevention of HIV. Three posters were shown at once next to each other and each time students had to decide which poster addresses the issue of HIV prevention for him/her the best. The reasons for their decisions had to be written down and then discussed with each other in pairs or triads before a whole class discussion took place. No indication was given by the lecturer which poster represents (or were tailor made for) which worldview.
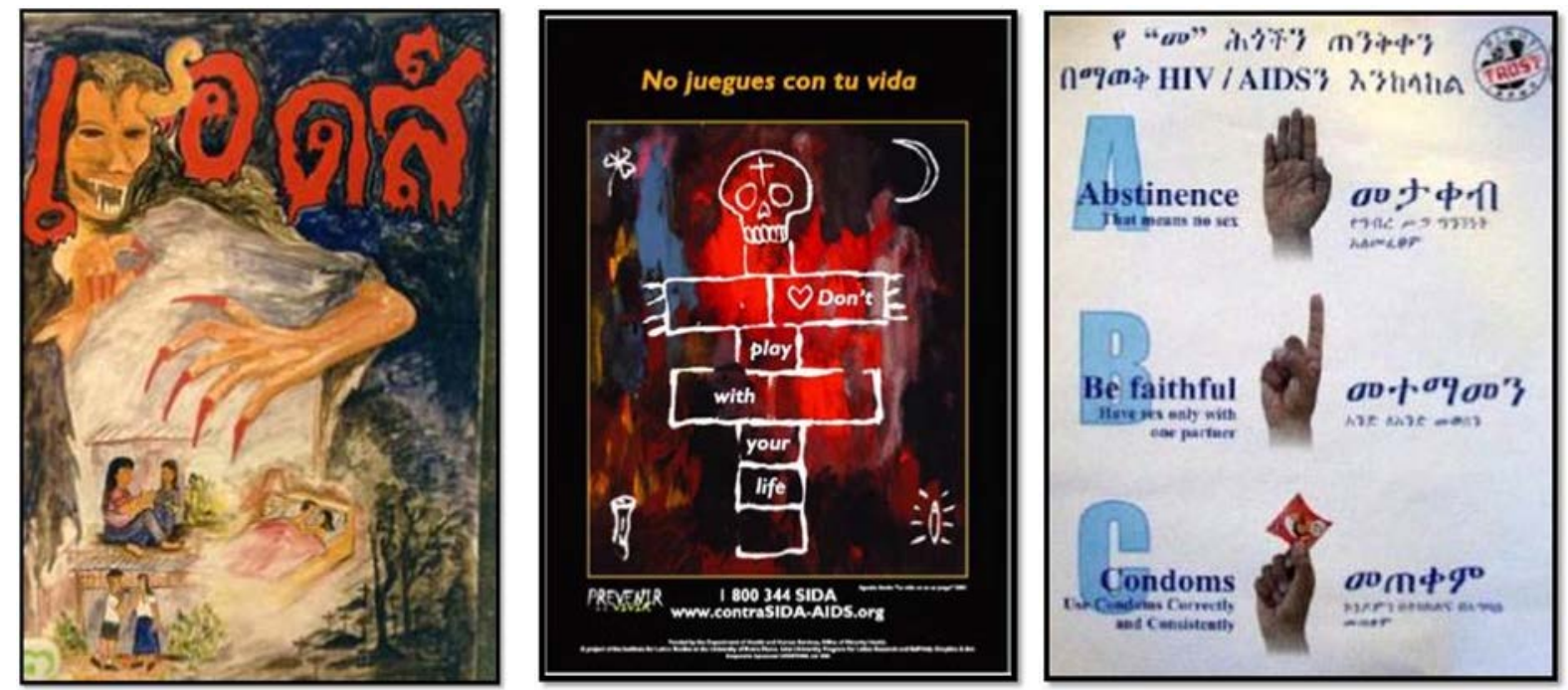

Figure 1: Example of posters that target the purple, red and blue worldviews (Brown and Beck 2009)

After three sets of posters were shown (with the same procedure of discussing it every time), the concept of worldviews was introduced and explained - specifically the three different worldviews the posters were tailor made for. The posters were shown again to the students, but this time with an indication of which worldview was targeted in each. Students could mark then 
which posters they had chosen and look at the reasons again why they had said those specific posters resonated with them the most.

\section{REFLECTION ON THE INFLUENCE OF THE STRATEGY ON STUDENT THINKING}

I claim that this exercise helped me to better meet the stated outcomes of this module. This statement is based on the findings that became apparent to me after reflecting on student responses in the UTW module:

\section{Students become aware of their own worldviews}

Some chose posters for different worldviews from different sets, but nearly all of them had at least two out of the three posters in one category of worldview. This exercise served as a sample test to see at least what the students' often hidden worldviews may look like. This was revealing and interesting for the students because for most it was the first time they had ever had a chance to identify and analyse their worldviews. This reflection exercise triggered the students' interest in worldviews and their need to further analyse their own ones. Even those students who initially denied that they have a worldview had to admit 'something hidden is at play in their lives' (Wilkens and Sandford 2009, 14) and they are generally curious to explore more about how this influences how they view various social issues. For example, as soon as the different worldviews for the different posters are explained, students typically react by saying: 'Now I understand why that poster addressed me' or 'Yes, that is the way I am thinking about life'.

\section{The posters incite reaction on an affective level}

Some students laugh because they are embarrassed by the sexual nature of the posters (see Figure 2), while others laugh because they find the 'superheroes' funny. Some students are shocked and disgusted to see such 'sexually explicit' posters in class and deem it inappropriate to be shown even in a class about HIV and AIDS (where sexuality needs to be discussed). I deal with this by leading a class discussion aimed at exposing the hidden worldviews underpinning these strong emotional reactions. This gives the students the opportunity to further explore their worldviews and to understand the cultural embeddedness and the influence of worldviews in their lives. By reflecting on their emotional reaction, the link between the complexity of HIV and AIDS and worldviews also becomes clear. Laughing, being disgusted or embarrassed about these posters reveals the judgmental role their worldviews can play when it comes to issues like sexuality. This exercise allows the students to experience on a very personal level the need for a more open worldview that respects diversity, is less judgemental 
and allows for constructive dialogue that leads towards greater understanding of difference.
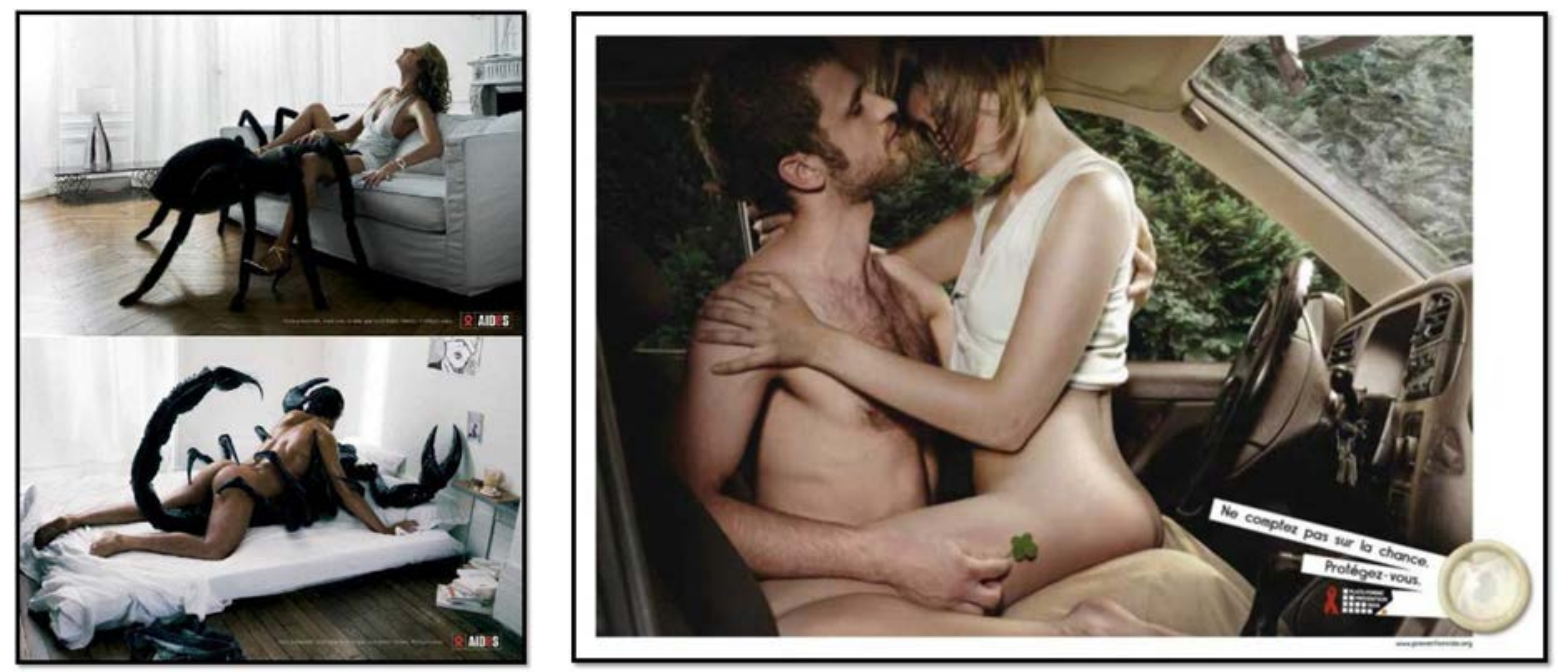

Figure 2: Examples of posters that students laughed at or reacted with disgust (Brown and Beck 2009)

\section{Students begin to understand the complexity of HIV}

I have observed time and again how students begin to become intrigued by the posters and keep looking at them - trying to see what it communicates; what does it really say about HIV/AIDS; why is this poster working better for people with a certain worldview; and why is it important to communicate this specific message? Students will for example say: 'What does the poster say about HIV prevention? I cannot get the message!', and then they help each other to discover the message. The posters create willingness to engage and renewed interest about HIV and AIDS and how they are conceptualized. Where students were previously apathetic or resistant to engaging in discussions about HIV and AIDS, I have seen them begin to develop an understanding of the social complexity of HIV and AIDS. For example, the use of different races in the posters, the gender roles portrayed, the different income groups, the levels of literacy and the discourses used - all differ in the posters to address different worldviews, while HIV and AIDS remain the constant. The posters helped in this way to communicate in a very visual way the link between a biological disease and the social issues that intersects with it.

The recognition of this link between HIV/AIDS and worldviews is of huge importance because: 1) it makes them aware of the potential influence of their worldviews on how they respond to social issues (this is then spelled out in more detail in the rest of the UTW module), and 2) it makes them aware of the judgmental character and potential exclusivity of their worldviews with regard to these issues. With the link between HIV and AIDS and worldviews established, recognized and realized on a personal level, the stage is set to continue to a more critical engagement into the complexities of the concepts worldviews, HIV and AIDS and its 
social complexity.

\section{CHALLENGING AND CHANGING WORLDVIEWS}

The findings discussed above indicate that my use of the prevention posters of Brown and Beck (2009) was useful to engender student interest in HIV and AIDS and to help them learn how their worldviews influenced their thinking about the disease and those who are affected by it. In the rest of the UTW module, the students' specific worldviews are critically discussed in order to deepen their understanding of their own views of HIV and related social issues. This is the first step in the process of challenging and changing their worldview in order to develop a more inclusive and nuanced understanding about the pandemic and its links to race, gender and economic status. For example, if a student has identified his worldview as a modern Western worldview, the individualistic nature of it will be analysed in class discussions through various texts. It helps them to think critically how their worldview can lead them to be exclusive, judgemental and uncaring of the plight of their fellow men. Van der Walt, talking about the modern Western worldview, says for example in this regard:

The contemporary Western view of man tends to result in a very reductionist anthropology. It has lost the broader view of man as a multi-faceted, multi-dimensional being. Man is reduced to: 1) an economic being (economism); 2) the individual aspect of his existence (individualism); 3) a rational-scientific being (scientism) and 4) a consumer of things that provide immediate satisfaction (hedonism). This Promethean man appreciates and uncritically accepts everything (e.g. technology) that may contribute towards his power to control, dominate and exploit reality. (Van der Walt 2003, 112)

This perspective on the modern Western worldview is also affirmed and broadened by Charles Taylor $(2007,475)$ with his emphasis on the authenticity of modern Western people:

Only after the Second World War this ethics of authenticity begins to shape the outlook of society in general. Expressions like 'do your own thing' become current ... Therapies multiply which promise to help you find yourself, realize yourself, release your true self, and so on.

These characteristics of the modern Western worldview are of course not necessarily bad, and discussing them helped students to gain a better understanding and insight into their worldview as modern Western people and how this worldview may influence their understanding of HIV and AIDS.

Typical responses of students include referring to the negative aspects, namely that a person with a modern Western worldview would typically not be interested or concerned about HIV and AIDS because he/she is too absorbed with his/her own individual life and ideals. Such 
a worldview may however - if it is consistently granted also for others to live out their own individualistic ideals - lead to a more proactive engagement with HIV and AIDS and its social intersectionality because such an engagement will enable more people to live their 'own' lives. A modern Western worldview may thus be detrimental in its understanding of HIV and AIDS, but a slight change in this worldview may make a huge positive difference. If, for example, there is at least the recognition of others' equal right of living a free and autonomous life, and on a deeper level a recognition of the interdependency of all human beings on each other (and the world they live in), the 'selfishness' of this worldview may be overcome to allow for a more empathic understanding of HIV and AIDS and those affected by it. For example, students will make the link between individualism and capitalism as part of the modern Western worldview and say 'we are controlled by capital (money) and consumerism' and 'money is the root of all evil' (quoted from their assignments and exam papers in the UTW module). Critique on the modern Western worldview may bring thus new insight into this worldview and how people with this worldview often involuntary or unknowingly tend to understand HIV as something that is not their problem if they are not infected with it. Without this crucial insight there will not be a possibility to change.

The Christian (or Biblical) worldview is another example of a common worldview with which the students identify. Such a worldview can be described as one where 'our place in the biblical story is to embody the good news that God is restoring the creation' (Goheen and Bartholomew 2008, 66). A classic definition of a Christian worldview is given by James Orr (1844-1913):

He who with his whole heart believes as Jesus as the Son of God is thereby committed to much else besides. He is committed to a view of God, to a view of man, to a view of sin, to a view of Redemption, to a view of a purpose of God in creation and history, to a view of human destiny found only in Christianity. This forms a 'Weltanschauung,' or a 'Christian view of the world' (Orr 1947, 4).

Most students with the Christian worldview are aware of the positive aspects of this worldview in terms of caring for the sick, loving your neighbour as yourself, making sacrifices for others, etc. It is only in the class discussion that these students become aware of this worldview's potential dangers. Some concerns identified by students about the Christian worldview are that it might be exclusive and judgmental. In other words, people with this worldview might be more willing to accept, care and love those who think and believe the same as they do and that it is very rigid when it comes to sexual morality. Both these aspects may lead to condemnation of those infected (or even affected) by HIV. For example, if HIV infection is understood within 
the Christian worldview as God's punishment for sexual immorality, this notion is used as an excuse not to get involved with the whole social issue of HIV. The judgmental attitude makes the situation even worse, because the attitude towards those affected is not only one of apathy, but one of punishment (by withholding resources, for example), which creates and sustains stigma. Students' thinking is disrupted through discussion of the need be more open to diversity, to be less judgmental, and to be more inclusive in order to deal with the complexities of HIV and AIDS. Without change in this attitude the intersectionality of HIV with other social issues like class, gender, and race, will also be denied or neglected.

Such change can only take place once students: 1 ) realize the link between worldviews and social issues like HIV, 2) recognize the influence of their worldviews on these issues, 3) identify what their own worldviews are, and 4) lastly are able to critique their own worldviews. The choosing of specific posters, and discussing the emotional reactions they incite, helps them to a large extent with the first three points. The posters also help in making clear how HIV and AIDS intersect with other social issues. The fourth point needs further discussion and clarification throughout the UTW module. Students are not expected to change their whole worldview completely, but at least to critically question its implications in dealing with all these social issues. For example, students are required to discuss their understanding of other pressing social issues like poverty, racism, environmental issues, corruption and globalization. They are then challenged to explain what changes are needed within their worldviews to enable them to understand and explain these issues from a more nuanced and inclusive perspective.

\section{HIV AND AIDS AS A TRANSFORMATIVE LENS IN HIGHER EDUCATION CURRICULA}

Although I have presented some evidence of shifts in students thinking around HIV and related issues, this is the only time in the programme that they are required to confront such issues. The UTW module can itself be improved by focussing more on HIV and AIDS - especially regarding its link with other social issues - but the need is also to improve, or rather transform, the whole social science programme by integrating HIV into other modules. HEAIDS (2007, 6) present 'four prominent models of curriculum infusion at higher education institutions, namely the compulsory model, the non-formal model, specialised courses and the integrated model'. While the UTW module is a compulsory module at the NWU, the module is not a 
specialised course on HIV. The compulsory model would be the best to describe this UTW module with because it is 1) a foundation level course in which HIV education is part of a credit-bearing programme, that is 2) assessed (HEAIDS 2007, 6-7). It is not part of an integrated model where HIV issues are incorporated into the structure of the degree programme - which is a serious point of critique if we are claiming to develop graduates who can 'create knowledge and promulgate discourse conducive to the eradication of the factors that drive the pandemic' - to quote the Policy framework on HIV and AIDS for higher education in South Africa (HESA 2008, 5).

The UTW module does address two needs that have been identified in recent publications of HEAIDS. The first is the problem that 'students experience so-called AIDS fatigue and do not respond to HIV and AIDS educational programmes' (HEAIDS 2007, 5). This 'AIDS fatigue' is countered by the presentation and discussion of the HIV prevention posters and their link to the students' worldviews. The emotional reaction and lively discussion in class by the students are telling in this regard, and the students' formal evaluation for this UTW module is also very positive ${ }^{3}$. However, for this module to be effective, it requires lecturers who understand the intersectionality of HIV and are able to present it within the context of students with diverse worldviews. This is especially necessary in the South African context, as Du Preez, Simmonds and Roux (2012) say: 'Teachers [must] become extended professionals who take ownership of their own development to emancipate themselves and their learners in a rationally and intuitively balanced manner (2012, 99).

The second need addressed by this UTW module is that 'almost all students and new graduates ... argued that higher education institutions should provide compulsory HIV/AIDS courses, both within and outside of the formal curriculum in structured, systematic and innovative ways' (HEAIDS 2010a, ix-x). Being a compulsory course, this UTW module indeed attempts to address HIV in this way. Students' positive reaction to this course, confirms this. However, there is a need to evaluate if this module has a lasting influence on student ontology and social interaction.

The biggest advantage of this UTW module - and its unique contribution to transforming the curriculum in higher education to be more relevant to our context - is that is does not see HIV/AIDS as something isolated, but as part of one's worldview, and how it links to social issues. If we think about a worldview as 'a set of presuppositions we hold - consciously or unconsciously - about the world we live in' (Sire 2009, 16) the encompassing nature and often hiddenness of worldviews are apparent. It is significant that James Sire (2004) defines a worldview as 'a commitment, a fundamental orientation of the heart, that can be expressed as 
a story or in a set of presuppositions (assumptions which may be true, partially true or entirely false) which we hold (consciously or subconsciously, consistently or inconsistently) about the basic constitution of reality, and that provides the foundation on which we live and move and have our being' (2004, 122). The implications of worldviews for our daily living are thus enormous, and the approaches from different worldviews to HIV can differ tremendously. Because worldview is such a fundamental part of our being, it should be questioned and criticised - especially if it leads to the denial of human rights and apathy towards those affected and infected by HIV. This UTW module attempts on a deeper level to help students to realise that 'HIV/AIDS interfaces with all social issues such as gender and sexuality, human rights, culture, the media, economy, morality, spirituality, protection and security and all aspects of an individual's life' (Chilisa, Bennel and Hyde 2001, 4). Such an approach may lessen the resistance to HIV integration into existing curricula because it sees it as an issue 'that touches on every aspect of the higher education sector' (HEAIDS 2007, 5).

There are however some shortcomings of this UTW module and approach. The first is that it is still a stand-alone module without integration with other courses. This is unfortunate, because research has indicated that 'the most sustainable interventions need to happen at a programmatic level' (HEAIDS 2010b, ix). Kelly (2001) highlights this point in his assessment of curriculum responses by universities: 'The curriculum response of universities to the imperatives of HIV/AIDS has been partly strong and weak. ... It is weak in that this has largely been an uncoordinated individual response, devoid of strong institutional roots, tending to be ad hoc, and insufficiently systematic or integrationist in its approach.' (2001, 9). Although it has been argued above that the UTW module has some strong characteristics of the integrated curriculum model, the understanding of HIV as a social issue and vehicle for challenging student thinking is still not infused throughout the formal curriculum. This confirms research that found that 'many faculties, schools and departments are incorporating aspects of HIV/AIDS in their courses and programmes, but that this is fragmented and uncoordinated' (HEAIDS 2010a, ix). The stand-alone UTW module - no matter how effective it is on challenging students' worldviews and consequent understanding of HIV - is therefore not sufficient and a more concerted effort on a programmatic level is necessary. A second critique concerns the prescriptive application of narrowly defined worldviews, rather than adopting a more generative approach where students are able to develop their own philosophical frameworks to understand the social and cultural world. If we are able to challenge students to interrogate their worldviews within the confines of this strictly prescribed course, imagine how much more scope there would be for transformational teaching within a less restricted context. 


\section{CONCLUSION}

The intersectionality of HIV with other social issues makes it a potential vehicle for transformation within higher education to develop a curriculum that is more relevant to our South African context. To understand this intersectionality better, and to approach these issues not only on a pragmatic level, the link between HIV and worldview should be understood. This article argued that the HIV prevention posters discussed by Brown and Beck (2009) are a very suitable tool to be used in this regard. By identifying and criticising their worldview, students may develop a more inclusive understanding of and approach to the implications of HIV for our society. It can help them to experience epistemological and ontological diversity not as a threat, but as an essential way of life. However, to effect lasting change in thinking and being, these ideas have to be infused into the entire programme to shift social science students from an exclusive and narrow minded worldview to one that is able to incorporate an intersectional understanding of the pressing issues facing contemporary South African society.

\section{NOTES}

1 For a historical analysis of the concept worldview, see Naugle (2002), Worldview: The history of a concept.

2 Of course this might seem to be a too broad generalization of the modern Western worldview, and there are many exceptions which make it difficult to conceptualize such a term. This critique is normally discussed as part of the UTW module.

3 The presentation of this module was evaluated by the students at the time the course was delivered and in 2013 the lecturer received a score of 92.75 per cent. The overall effectiveness of the module has however not been evaluated. It also needs to be explored how effective the module is changing students' attitude about HIV/AIDS in two or three years after the students have completed it.

\section{REFERENCES}

Brown, B. C. and D. E. Beck. 2009. How to tailor public communications about HIV/AIDS to different worldviews. http://debategraph.org/Handler.ashx?path=ROOT\%2Fu13592\%2FBarrett+Brown_ Don+Beck_Communicating+About+HIV-AIDS+to+Different+Worldviews.pdf (accessed 2 June 2015).

Chilisa, B., P. Bennel and K. Hyde. 2001. The impact of HIV/AIDS on the University of Botswana: Developing a comprehensive strategic response. United Kingdom: Department for International Development.

Du Preez, P., S. Simmonds and C. Roux. 2012. Teaching-learning and curriculum development for human rights education: Two sides of the same coin. Journal of Education 55: 83-103.

Goheen, M. and C. Bartholomew. 2008. Living at the crossroads. An introduction to Christian worldview. London: SPCK.

Goldman, A. H. 2007. Plain sex. In Ethics in practice: An anthology, ed. H. LaFollette, 282-289. Massachusetts: Blackwell Publishers.

HEAIDS. 2007. Case studies in mainstreaming: Integrating HIV and AIDS realities into South African higher education curricula. Pretoria: HESA. 
HEAIDS. 2010a. An investigation of graduate competency for managing HIV/AIDS in the workplace. Pretoria: Higher Education South Africa.

HEAIDS. 2010b. Creating space for HIV and AIDS in the curriculum: Rapid assessment of curricular responses. Pretoria: HESA.

HESA see Higher Education South Africa.

Higher Education South Africa. 2008. Policy framework on HIV and AIDS for higher education in South Africa. Pretoria: HESA.

Kelly, M. J. 2001. The response of information technology to the challenge of HIV/AIDS in higher education institutions in Africa. A paper presented at the 'Reforms in Higher Education and the Use of Information Technology in Africa’ conference. Nairobi, Kenya: November.

Naugle, D. K. 2002. Worldview: The history of a concept. Grand Rapids: Eerdmans.

Olthuis, J. H. 1989. On worldviews. In Stained glass: Worldviews and social science, ed. P. A. Marshall, S. Griffioen and R. J. Mouw, 1-12. University Press of America: Landham.

Orr, J. 1947 1893. The Christian view of God and the World. Grand Rapids: Eerdmans.

Sire, J. W. 2004. Naming the elephant. Worldview as a concept. Downers Grove, Il: Intervarsity Press.

Sire, J. W. 2009. The universe next door. A basic worldview catalog. Downers Grove, Il: Intervarsity Press.

Steyn, M. 2014. Critical diversity literacy: Essentials for the twenty-first century. In Routledge International Handbook of Diversity Studies, ed. S. Vertovec, 379-388. London: Taylor and Francis.

Steyn, M., H. McEwan and C. Kelly. 2010. Diversity literacy. https://vula.uct.ac.za/access/ content/group/49399abf-1244-4e86-94d4-1e8955bf14d1/Diversity\%20Literacy/Diversity\%20 Literacy/Syllabus\%20_\%20Overview/Diversity\%20Literacy.pdf (accessed 6 April 2016).

Taylor, C. 2007. A secular age. Massachusetts: Belknap Press of Harvard University Press.

Van der Walt, B. J. 2003. Understanding and rebuilding Africa. From desperation today to expectation for tomorrow. Potchefstroom: Institute for Contemporary Christianity in Africa.

Verhoef, A. H. 2014. Understanding the cultural/social and political world. A study guide for WVCS221. North-West University, Potchefstroom: Ivyline.

Volks, C. 2012. Third degree: AIDS review. Pretoria: Centre for the Study of AIDS.

Wilkens, S. and M. L. Sanford. 2009. Hidden worldviews: Eight cultural stories that shape our lives. Downers Grove, IL: Intervarsity Press.

Wood, L. 2011a. HIV and AIDS education in pre-service teacher programmes: Lessons learned from experience in a Post-Graduate Certificate in Education. Acta Academica 43(4): 181-202.

Wood, L. 2011b. Faculty views of HIV and AIDS education in the curriculum at tertiary level. South African Journal of Higher Education 25(4): 819-837. 